\title{
ACTION OF THE ANTIBIOTICS OF THE ITURIN GROUP ON ARTIFICIAL MEMBRANES ${ }^{\dagger}$
}

\author{
Françoise Besson and Georges Michel \\ Laboratoire de Biochimie Microbienne, Université Claude Bernard, \\ Lyon I, 43 Boulevard du 11 Novembre 1918, 69622 Villeurbanne Cedex, France
}

(Received for publication February 29, 1984)

\begin{abstract}
The action of iturin $\mathrm{A}$ and bacillomycin $\mathrm{L}$ on vesicles of dipalmitoylphosphatidylcholine (DPPC) and DPPC-cholesterol was studied. Iturin A destroyed the vesicles, bacillomycin L bound with DPPC vesicles and destroyed vesicles containing DPPC and cholesterol. These results are discussed in comparison with the action of antibiotics of the iturin group on cytoplasmic membranes.
\end{abstract}

Two antibiotics, iturin A and bacillomycin $\mathrm{L}$ have been isolated from strains of Bacillus subtilis. Their structures have been determined ${ }^{1,2)}$ as cyclic peptidolipids constituted by a $\beta$-amino acid with 14 to 16 carbon atoms ${ }^{3)}$ and a macrocyclic peptide with $\mathrm{D}$ and $\mathrm{L} \alpha$-amino acids.

These antibiotics have a restricted antibacterial activity against a few bacteria such as Micrococcus luteus and a wider antifungal spectrum. A lytic activity upon the protoplasts of M. luteus has been observed, consistent with an action on the cytoplasmic membranes ${ }^{4,5)}$ but did not explain completely the antibacterial properties: Iturin A lysed the protoplasts, bacillomycin L was found to have no lytic activity while its derivative, bacillomycin L-dimethyl ester, had a high lytic activity on $M$. luteus protoplasts ${ }^{5,8}$. These differences could be attributed to the difference of polarity of the peptidic part of antibiotics and derivatives.

In order to confirm the action of these antibiotics on the cytoplasmic membrane, iturin A, bacillomycin $\mathrm{L}$ and bacillomycin L-dimethyl ester were incubated with human erythrocytes, and all these compounds were found to be hemolytic ${ }^{\text {T) }}$.

The difference observed between lytic and hemolytic activities can be attributed to the difference of composition of the cytoplasmic membranes of M. luteus and of the erythrocytes. In order to determine the importance of the polarity of the antibiotics and the role of the lipid composition of the membrane, we studied the action of iturin $\mathrm{A}$, a slightly polar compound and bacillomycin $\mathrm{L}$, an anionic compound, on artificial membranes, dipalmitoylphosphatidylcholine vesicles with or without cholesterol.

\section{Materials and Methods}

Antibiotics

Iturin A was prepared as described previously ${ }^{3)}$.

Bacillomycin L was a gift of Dr. G. H. WARren, Wyeth Institute of Applied Biochemistry, West Chester, Pensylvania, U.S.A.

$\underline{\text { Lipids }}$

Dipalmitoylphosphatidylcholine was purchased from Sigma Chem. Co., cholesterol from Prolabo (France), di-[1-14 C]palmitoyl-L- $\alpha$-diphosphatidylcholine from the Radiochemical Centre, Amersham (England) $(114 \mathrm{mCi} / \mathrm{mmol})$ and $\left[1,2-{ }^{3} \mathrm{H}\right]$ cholesterol from the Commissariat à l'Energie Atomique, Saclay

+ This paper is dedicated to the memory of Elisabeth BESSON. 
(France) (1 Ci/mmol).

Preparation of Radioactive Vesicles

$50 \mathrm{mg}$ of radioactive dipalmitoylphosphatidylcholine (DPPC) $(0.5 \mu \mathrm{Ci} / \mathrm{mg})$ were sonicated in $10 \mathrm{ml}$ of a $0.05 \mathrm{M}$ Tris- $\mathrm{HCl}-0.10 \mathrm{M} \mathrm{NaCl}$ buffer $\mathrm{pH} 8.5$ under nitrogen atmosphere at $45^{\circ} \mathrm{C}$ in a MSE apparatus. When vesicles contained cholesterol, $5 \mathrm{mg}$ of radioactive cholesterol $(40 \mu \mathrm{Ci} / \mathrm{ml})$ were added to DPPC. Vesicles formation was followed by turbidimetry at $300 \mathrm{~nm}$. When the absorbance was stable, vesicles were prepared by chromatography on a Sepharose $4 \mathrm{~B}$ column at $45^{\circ} \mathrm{C}$ according to the HUANG procedure $^{8)}$. Separation of bilayer vesicles and larger vesicles was followed by measuring the radioactivity of a $50 \mu 1$ aliquot of each fraction. Multilamellar vesicles were excluded from the gel and separated from bilayer vesicles. Further experiments were done on the radioactive bilayer vesicles.

\section{Binding between Radioactive Vesicles and Antibiotics}

Interaction between radioactive vesicles and iturin $\mathrm{A}$ or bacillomycin $\mathrm{L}$ was quantitated by the general method of HuMmeL and DREYER ${ }^{9)}$. The $\left[{ }^{14} \mathrm{C}\right] \mathrm{DPPC}$ vesicles with or without $\left[{ }^{3} \mathrm{H}\right]$ cholesterol were diluted in a $0.05 \mathrm{M}$ Tris- $\mathrm{HCl}-0.10 \mathrm{M} \mathrm{NaCl}$ buffer, $\mathrm{pH} 8.5$ to a final concentration of about $100 \mu \mathrm{g}$ lipids $/ \mathrm{ml}$ and passed through a $4.5 \mathrm{ml}$ column of a gel at $45^{\circ} \mathrm{C}$. Two types of gel were used: Sephadex G-25 from which the phospholipid vesicles were excluded and Sepharose 4B from which they were not excluded. The fractions $(150 \mu \mathrm{l})$ were collected and counted in $2 \mathrm{ml}$ of Aqualuma (Beckman). When the radioactivity of the eluate was constant, $100 \mu \mathrm{l}$ of a mixture containing vesicles and various amounts of antibiotic was added on the column and the elution was continued with the vesicle suspension.

If the antibiotic pulled out the lipids from the vesicles, these lipids were retained in Sephadex G-25 gel and the elution profile showed a hole followed by a peak ${ }^{10,11)}$. If the antibiotic gave a complex of larger size with vesicles, this complex was extruded from the Sepharose 4B gel and the elution profile showed a peak followed by a trough ${ }^{12)}$.

\section{Characterization of Antibiotics}

The presence of antibiotics was tested by hydrolysis of the eluates with $6 \mathrm{~N} \mathrm{HCl}$ for 8 hours

Fig. 1. Action of iturin $\mathrm{A}$ on $\left[{ }^{14} \mathrm{C}\right] \mathrm{DPPC}$ vesicles. Elution profiles on a column of Sephadex G-25; the addition of iturin $\mathrm{A}$ was indicated by the arrows.

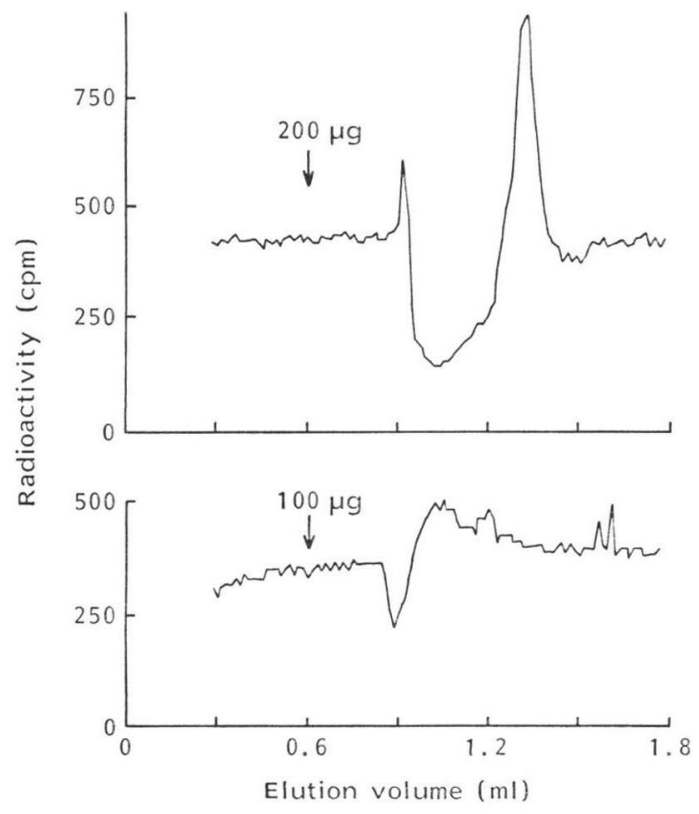

Fig. 2. Action of iturin A on $\left[{ }^{[4} \mathrm{C}\right] \mathrm{DPPC}-\left[{ }^{3} \mathrm{H}\right]-$ cholesterol vesicles.

Elution profiles on a column of Sephadex G-25; the addition of iturin $\mathrm{A}(100 \mu \mathrm{g})$ was indicated by the arrows.

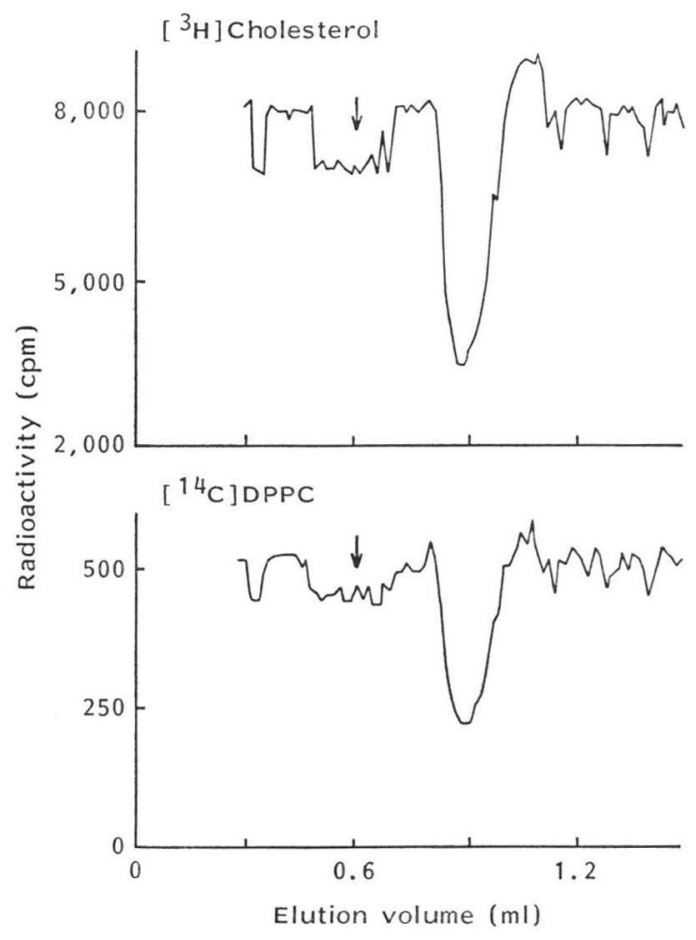


at $150^{\circ} \mathrm{C}$, followed by the determination of aspartic acid, a common amino acid to both antibiotics, according to the method of GHUYSEN et al. ${ }^{13)}$.

\section{Results}

\section{Action of Iturin A on Phospholipidic Vesicles}

Both kinds of phospholipidic vesicles, DPPC and DPPC-cholesterol vesicles, were excluded from Sephadex G-25 column. The addition of iturin A to the column gave modifications of the elution profiles (Figs. 1 and 2) which showed a trough followed by a peak. The measure of the radioactivity in all the fractions gave a constant $\left[{ }^{14} \mathrm{C}\right] /\left[{ }^{3} \mathrm{H}\right]$ ratio; thus iturin A had no selectivity for phospholipid or cholesterol.

A quantitative analysis of iturin $\mathrm{A}$ in the eluates indicated that all the antibiotic was localized in the peak of phospholipids. When iturin A was passed on a column of Sephadex G-25 in the absence of vesicles, the major part was excluded from the column (Fig. 3); thus, in this case the molecules of iturin A must be associated in a micellar form and they are not retained on the column. In the presence of vesicles, iturin A is included in Sephadex G-25 gel and eluted with the peak of phospholipids.

In fact, the result of the interaction between iturin $\mathrm{A}$ and the phospholipidic vesicles is a disruption of both vesicles and iturin A micelles with the formation of a new association of small size between the lipid and the antibiotic.

Fig. 3. Action of iturin $\mathrm{A}$ on $\left[{ }^{14} \mathrm{C}\right] \mathrm{DPPC}$ vesicles. Elution profiles on a column of Sephadex G-25, a) in the presence of vesicles, b) in the absence of vesicles; the addition of iturin $\mathrm{A}(200 \mu \mathrm{g})$ was indicated by the arrows.

- Radioactivity of the eluate, $\bigcirc$ amounts of iturin A.

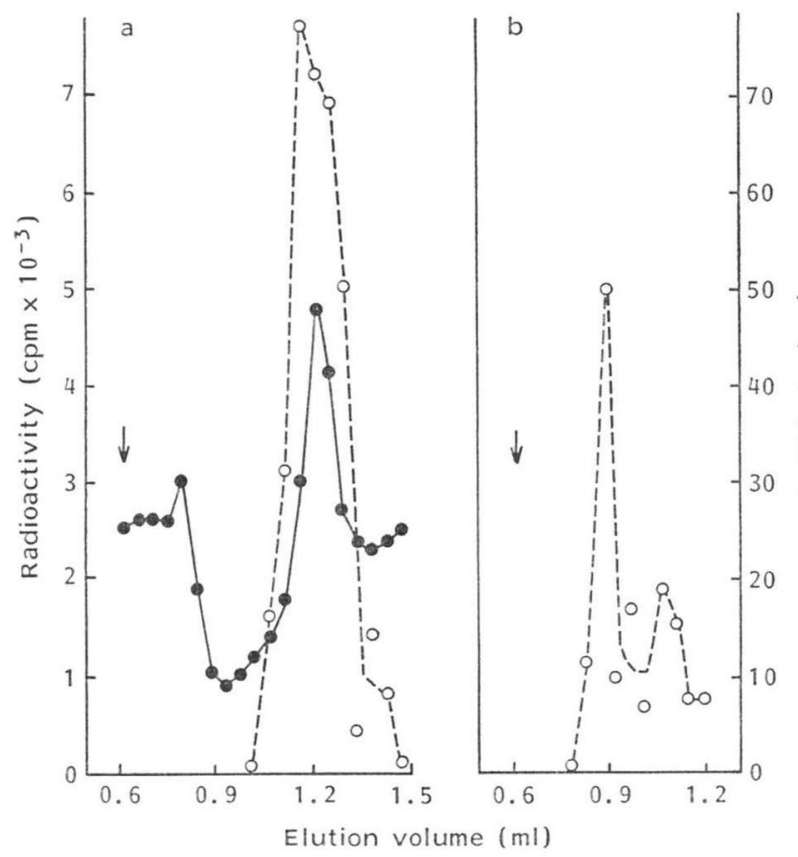

Fig. 4. Action of bacillomycin $\mathrm{L}$ on $\left[{ }^{14} \mathrm{C}\right] \mathrm{DPPC}$ vesicles.

Elution profiles on a column of Sepharose 4B; the addition of bacillomycin $\mathrm{L}$ was indicated by the arrows.

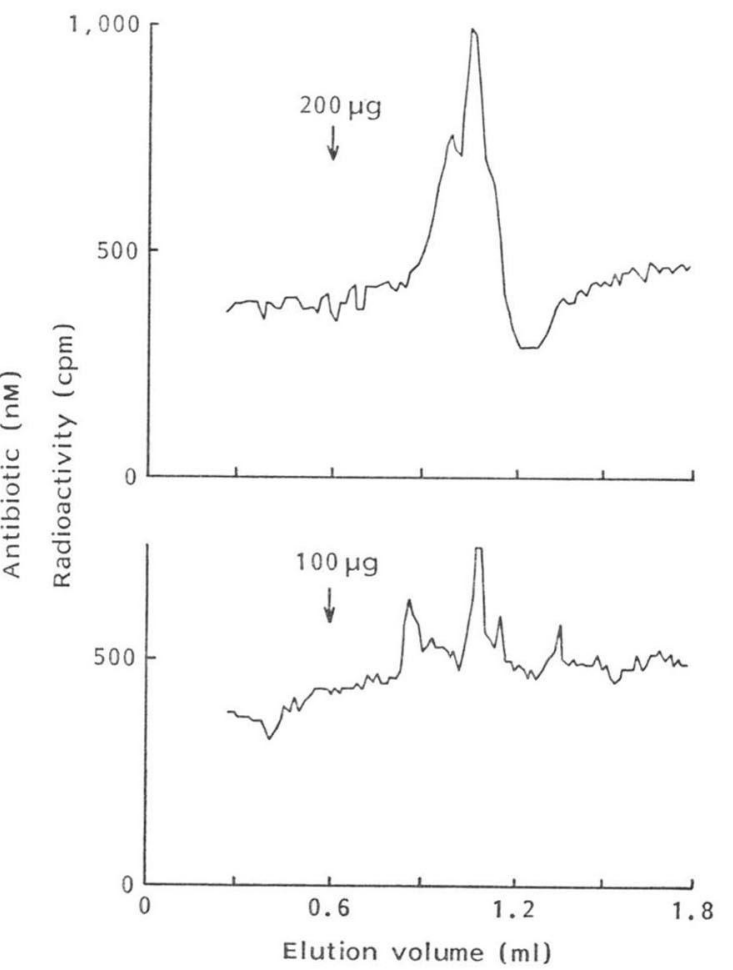


Fig. 5. Action of bacillomycin $\mathrm{L}$ on $\left[{ }^{14} \mathrm{C}\right] \mathrm{DPPC}$ vesicles.

Elution profiles on a column of Sepharose 4B, a) in the presence of vesicles, b) in the absence of vesicles; the addition of bacillomycin $\mathrm{L}(200 \mu \mathrm{g})$ was indicated by the arrows.

- Radioactivity of the eluate, $O$ amounts of bacillomycin L.

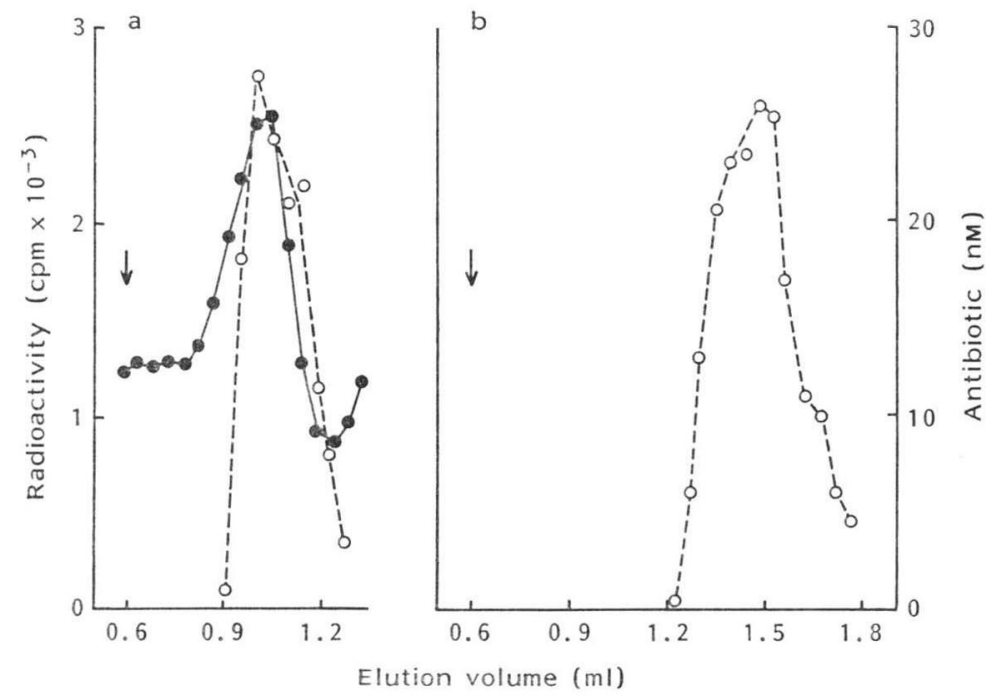

Action of Bacillomycin L on

Phospholipidic Vesicles

Bacillomycin $\mathrm{L}$ was added to DPPC vesicles on a column of Sepharose 4B. The results (Fig. 4) show the presence of a peak of radioactive material followed by a trough. By titration the antibiotic was found essentially in this peak (Fig. 5). These results agree with the formation of a complex between the antibiotic and the vesicles (see Materials and Methods).

Interaction between bacillomycin $\mathrm{L}$ and vesicles containing DPPC and cholesterol are shown on Fig. 6. The results are quite different from those in the absence of cholesterol, the action of bacillomycin $\mathrm{L}$ is similar to that of iturin A, giving a trough followed by a peak of radioactivity.

\section{Discussion}

Previous work had given some unexplained results on the action of iturin A and bacillomycin L on $M$. luteus, protoplasts from $M$. luteus and erythrocytes. While both antibiotics were active on $M$. luteus and erythrocytes, iturin A lysed the protoplasts and bacillomycin L did not. This difference is probably a consequence of the structures of
Fig. 6. Action of bacillomycin $\mathrm{L}$ on $\left[{ }^{14} \mathrm{C}\right] \mathrm{DPPC}$ $\left[{ }^{3} \mathrm{H}\right]$ cholesterol vesicles.

Elution profiles on a column of Sephadex G-25; the addition of bacillomycin $\mathrm{L}(200 \mu \mathrm{g})$ was indicated by the arrows.

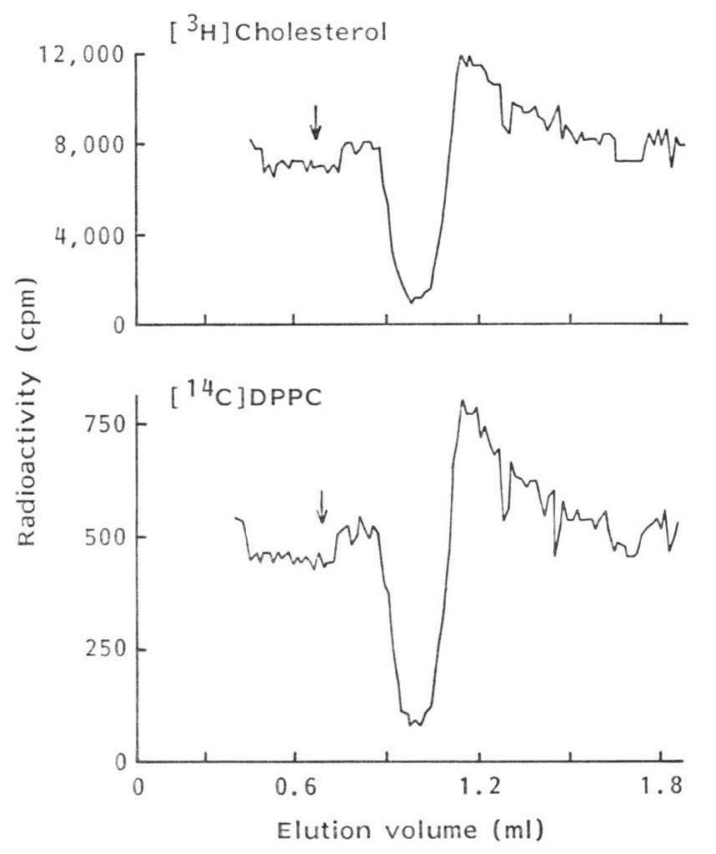


these antibiotics: Iturin A has a non polar cyclic peptide ${ }^{1)}$ and bacillomycin has an anionic cyclic pepti$\mathrm{de}^{2)}$. The purpose of this work was to test the action of these antibiotics on phospholipidic vesicles.

In a buffer solution, $\mathrm{pH} 8.5$, iturin $\mathrm{A}$ was present in a micellar form. When vesicles containing DPPC or DPPC-cholesterol were added to the solution, a disruption of micelles and of vesicles was observed and the molecules of antibiotics and of lipids were associated in small size complexes which were retained in Sephadex G-25 gel; the interaction vesicles-iturin A corresponds to a "solubilization" of the vesicles.

In the presence of bacillomycin L, DPPC vesicles were not destroyed but the antibiotic was incorporated in the vesicles giving aggregates of larger size than DPPC vesicles. When the vesicles contained DPPC and cholesterol, bacillomycin L destroyed the vesicles as did iturin A.

These results were in agreement with the action of antibiotics on protoplasts from M. luteus and on erythrocytes. Iturin A destroyed the protoplasts and lysed erythrocytes by removing lipidic components. Bacillomycin L bound to protoplasts and no solubilization was found. With erythrocytes which contain cholesterol, the action of bacillomycin $L$ was different, erythrocytes were destroyed as were the vesicles containing DPPC and cholesterol.

Recent studies on the interaction of iturin A and bacillomycin L with DPPC vesicles for low concentration of antibiotics (ratio antibiotic/phospholipids $=0.2$ ) had shown an association of both antibiotics with vesicles ${ }^{14)}$. In the present work, with high concentration of antibiotics (ratio antibiotic/ phospholipids =10) the behavior of iturin A is found to be different, the antibiotic pulls out the phospholipid molecules from the vesicles while bacillomycin $L$ gives an association vesicle-antibiotic of larger size, whatever the antibiotic concentration.

\section{Acknowledgments}

This work was supported by the Centre National de la Recherche Scientifique (E.R.A. $n^{\circ} 852$ and A.T.P. Microbiologie 1981).

\section{References}

1) Peypoux, F.; M. Guinand, G. Michel, L. Delcambe, B. C. Das \& E. Lederer: Structure of iturin A, a peptidolipid antibiotic from Bacillus subtilis. Biochemistry 17: 3992 3996, 1978

2) Besson, F.; F. Peypoux, G. Michel \& L. Delcambe: Structure de la bacillomycine L, antibiotique de Bacillus subtilis. Eur. J. Biochem. 77: 61 67, 1977

3) Peypoux, F.; M. Guinand, G. Michel, L. Delcambe, B. C. Das, P. Varenne \& E. Lederer: Isolement de l'acide 3-amino 12-méthyl tétradécanoïque et de l'acide 3-amino 12-méthyl tridécanoïque à partir de l'iturine, antibiotique de Bacillus subtilis. Tetrahedron 29: 3455 3459, 1973

4) Besson, F.; F. Peypoux, G. Michel \& L. Delcambe: Mode of action of iturin A, an antibiotic isolated from Bacillus subtilis, on Micrococcus luteus. Biochem. Biophys. Res. Commun. 81: 297 304, 1978

5) Besson, F.; F. Peypoux \& G. Michel: Action of mycosubtilin and of bacillomycin L on Micrococcus luteus cells and protoplasts; influence of the polarity of the antibiotics upon their action on the bacterial cytoplasmic membrane. FEBS Lett. 90: 36 40, 1978

6) Besson, F.; F. Peypoux \& G. Michel: Interactions between bacterial membranes and peptidolipids: Lysis of Micrococcus luteus protoplasts by derivatives of peptidolipidic antibiotics from Bacillus subtilis. Biochim. Biophys. Acta 552: 558 562, 1979

7) Quentin, M. J.; F. Besson, F. Peypoux \& G. Michel: Action of peptidolipidic antibiotics of iturin group on erythrocytes: Effect of some lipids on hemolysis. Biochim. Biophys. Acta 684: 207 211, 1982

8) Huang, C.: Studies on phosphatidylcholine vesicles. Formation and physical characteristics. Biochemistry 8: $344 \sim 352,1969$

9) Hummel, J. P. \& W. J. Dreyer: Measurement of protein-binding phenomena by gel filtration. Biochim. Biophys. Acta 63: 530 532, 1962

10) Storm, D. R. \& J. L. Strominger: Binding of bacitracin to cells and protoplasts of Micrococcus lysodeikticus. J. Biol. Chem. 249: 1823 1827, 1974

11) Rosenthal, K. S.; P. E. Swanson \& D. R. Storm: Disruption of Escherichia coli outer membranes by EM49. A new membrane active peptide antibiotic. Biochemistry 15: 5783 5792, 1976 
12) Storm, D. R. \& J. L. Strominger: Complex formation between bacitracin peptides and isoprenyl pyrophosphates. J. Biol. Chem. 248: 3940 3945, 1973

13) Ghuysen, J. M.; D. J. Tipper \& J. L. Strominger: Enzymes that degrade bacterial cell walls. In Methods in Enzymology. Vol. 8, pp. 685 699, Academic Press, New York, 1966

14) Quentin, M. J.; F. Peypoux \& G. Michel: Changes in phospholipid vesicles size induced by amphipathic antibiotics of iturin group. Biochem. Int. 7: 63 70, 1983 